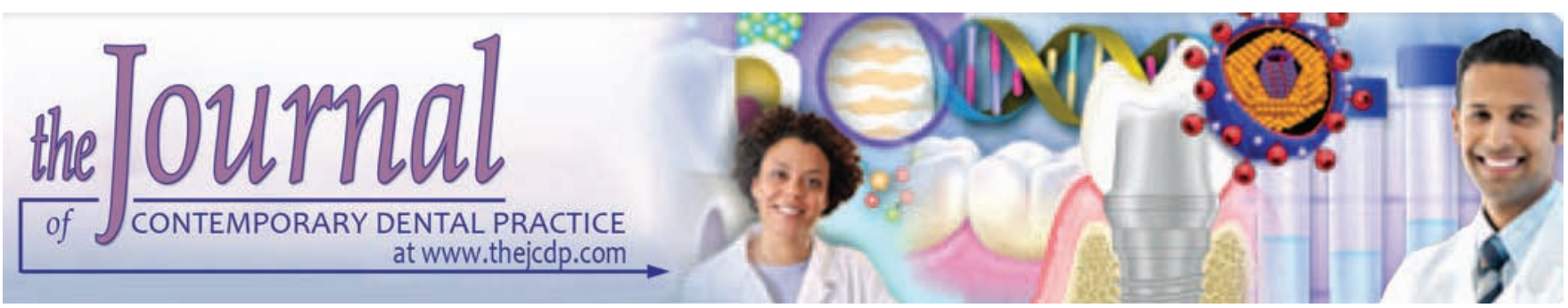

\title{
Orthopedic Effect of Chin Cup during Mixed Dentition Stage
}

\author{
${ }^{1}$ Hussein N Al-Khalifa, ${ }^{2}$ Mohamed I Hashem, ${ }^{3}$ Khalid J Alanazi, ${ }^{4}$ Sukumaran Anil
}

\begin{abstract}
Introduction: Chin cup (CC) therapy has been used as the traditional appliance for treating class III malocclusion during mixed dentition period. The aim of this study was to investigate the effect of CC on the improvement of skeletal and dentoalveolar skeletal changes in class III patients during mixed dentition stage.
\end{abstract}

Materials and methods: A total of 30 patients (7-9 years old) with skeletal class III malocclusion were selected based on clinical and cephalometric examination. Out of 30 patients, 20 underwent CC therapy. All orthodontic records and measurements were taken before and after treatment. Similar records were collected from the control group. The lateral cephalometric films were traced before and after treatment and analyzed.

Results: There was a significant improvement in maxillary and the mandibular skeletal measurements after CC therapy. Improvement of ANB angle and an increase in Wits appraisal have been detected in the treated group according to intermaxillary skeletal variables.

Conclusion: The study concluded that the CC therapy is effective for correcting skeletal class III malocclusion along with positive changes in the dentoskeletal variables during the mixed dentition stage.

\footnotetext{
${ }^{1}$ Department of Orthodontics, College of Dentistry, Al-Azhar University, Cairo, Egypt

${ }^{2}$ Department of Dental Health, Dental Biomaterials Research Chair, College of Applied Medical Sciences, King Saud University, Riyadh, Kingdom of Saudi Arabia; Dental Biomaterials Department, College of Dentistry, Al-Azhar University, Cairo Egypt

${ }^{3}$ Department of Pediatric Dentistry, Riyadh Colleges of Dentistry and Pharmacy, Riyadh, Kingdom of Saudi Arabia

${ }^{4}$ Department of Preventive Dental Sciences, College of Dentistry Prince Sattam Bin Abdulaziz University, Riyadh, Kingdom of Saudi Arabia

Corresponding Author: Hussein N Al-Khalifa, Department of Orthodontics, College of Dentistry, Al-Azhar University, Cairo Egypt, e-mail: ksucod@gmail.com
}

Keywords: Chin cup, Growing children, Maxillary protraction, Mixed dentition, Skeletal class III malocclusion.

How to cite this article: Al-Khalifa HN, Hashem MI, Alanazi KJ, Anil S. Orthopedic Effect of Chin Cup during Mixed Dentition Stage. J Contemp Dent Pract 2017;18(5):410-414.

\section{Source of support: Nil}

Conflict of interest: None

\section{INTRODUCTION}

Chin cup (CC) therapy has been widely used as the traditional appliance for treating class III malocclusion. Chin cup is the preferred appliance for growing children with mandibular prognathism. ${ }^{1-3}$ Chin cup is designed to suppress and/or redirect the mandibular growth, close the gonial angle, and remodel the mandibular and temporomandibular joint. The CC appliances can be divided into two subcategories: The vertical pull CC and the occipital pull CC. The vertical pull CC is an orthopedic extraoral appliance designed and used to address problems associated with lower face height and/or open bite, which can accompany class III or class I malocclusions. ${ }^{4}$ Unlike other extraoral appliances, vertical pull CC should be worn during or shortly after the pubertal period, treatment lasts for 1 or 2 years depending on the severity of the case with this type of appliances. ${ }^{5}$

The other type of CC appliance is occipital pull $\mathrm{CC}$ and is used in anteroposterior problems and, specifically, class III malocclusion. Contrary to vertical CC, occipital pull CC is used for moderate orthopedic class III problems for the age group between 4 and 9 years. ${ }^{6}$ It can also be worn during the retention period following face mask treatment. ${ }^{7}$ Factors, such as age and sex of the patient have to be given important consideration during the CC therapy. The duration of wearing the device could range from 8 to 10 hours a day. ${ }^{3}$

Despite the advantages of the CC appliance, clinical results of using CC proved to be a matter of debate. ${ }^{8,9}$ The 


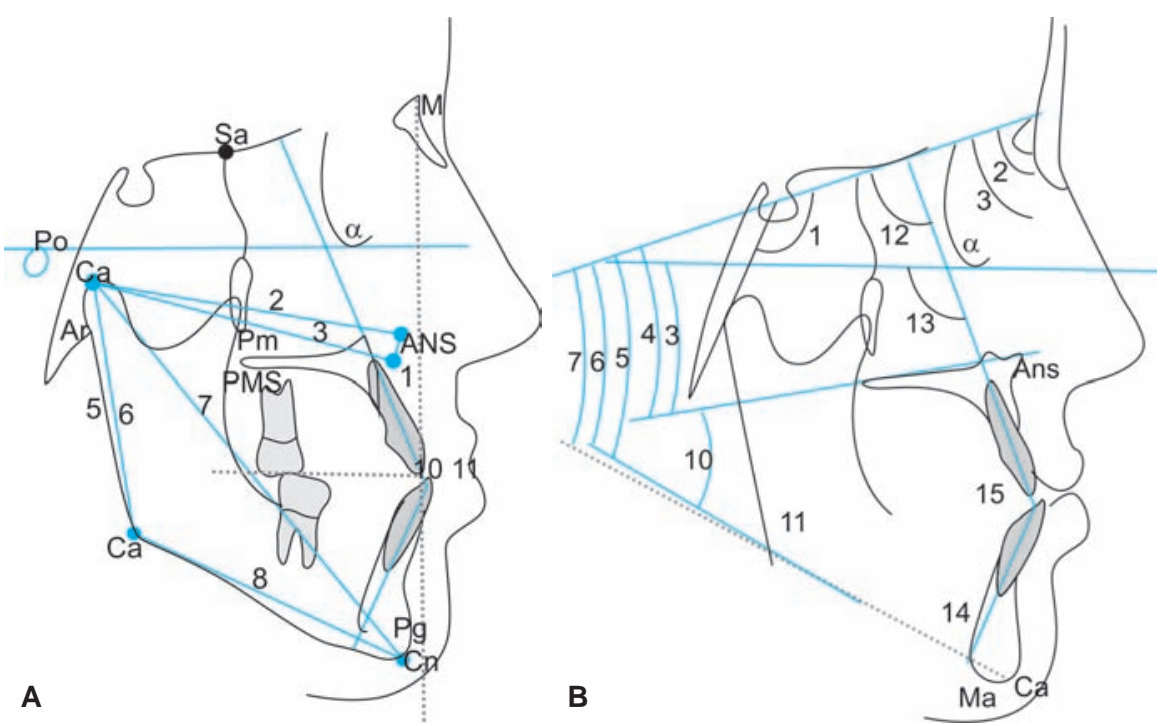

Figs 1A and B: (A) Cephalometric linear measurements: (1) A to $N$ perpendicular, (2) Co-ANS, (3) Co-A, (4) Pg to N perpendicular, (5) Co-Go, (6) Ar-Go, (7) Co-Gn, (8) Go-Gn, (9) Wits appraisal, (10) Overjet, (11) Overbite; and (B) cephalometric angular measurements: (1) NSBa, (2) SNA, (3) SNB, (4) ANB, (5) SN-PP, (6) SN-GoMe, (7) SN-GoGn, (8) FH-palatal plane (PP), (9) FH-mandibular plane (MP), (10) PP-MP, (11) gonial angle, (12) U1-SN, (13) U1-FH, (14) incisor mandibular plane angle (IMPA), (15) interincisal angle

usage of CC reveals contradictions regarding their use and clinical effectiveness. Several cephalometric variables are found to be affected by the $\mathrm{CC}$ use, such as reduction of the SNB (sella, nasion, B point) and the gonial angle, increase in the anterior facial height, increase of the overjet $(\mathrm{OJ})$, and slight reduction of the overbite $(\mathrm{OB}){ }^{10,11}$ It is also used to open the bite along with an intraoral appliance or a bite-plate. ${ }^{12,13}$ The reduction of SNB angle leads to restriction on the mandibular growth, significant rotation of the mandible, and significant increase of the OJ.2,14 On the contrary, other studies revealed that using CC in class III malocclusion results in increased $\mathrm{OB}$ and negative OJ. ${ }^{15}$ The objective of the study was to evaluate the skeletal and dentoalveolar changes in class III malocclusion treated with CC therapy.

\section{MATERIALS AND METHODS}

The study was conducted on 30 patients with skeletal class III malocclusion. Patients selected ranged from 7 to 9 years of age and were followed up for 10 months. The study was approved by the institutional review board. Patients were selected from the Orthodontic Department of the Faculty of Dental Medicine in Al-Azhar University, Egypt. Out of 30 patients, 20 had undergone CC therapy with maxillary bite block. The remaining 10 subjects who did not undergo the treatment were included as control group.

Selection of patients in both groups was made according to the following criteria: (1) Skeletal class III relationship with normal maxilla and prognathic mandible, (2) all patients had no transverse discrepancy between dental arches, (3) no craniofacial anomaly, (4) no history of previous orthodontic treatment, (5) all patients had class III malocclusion in the mixed dentition stage, and (6) patients and parents are cooperative with the dentist.

The orthodontic records were taken for all patients. Lateral cephalometric films were taken to analyze the pre- and posttreatment changes resulted from using CC, and appliances were worn for 12 to 14 hours a day with force magnitude $600 \mathrm{gm}$ per side. At the beginning of the treatment (T1) and the end (T2), lateral cephalograms were taken. The analysis used for all cephalograms in this study contained measurements from several analyses. In addition, the researcher used lateral cephalometric films to determine linear and angular measurements as in Figures 1A, B, 2A and B. Furthermore, for establishing

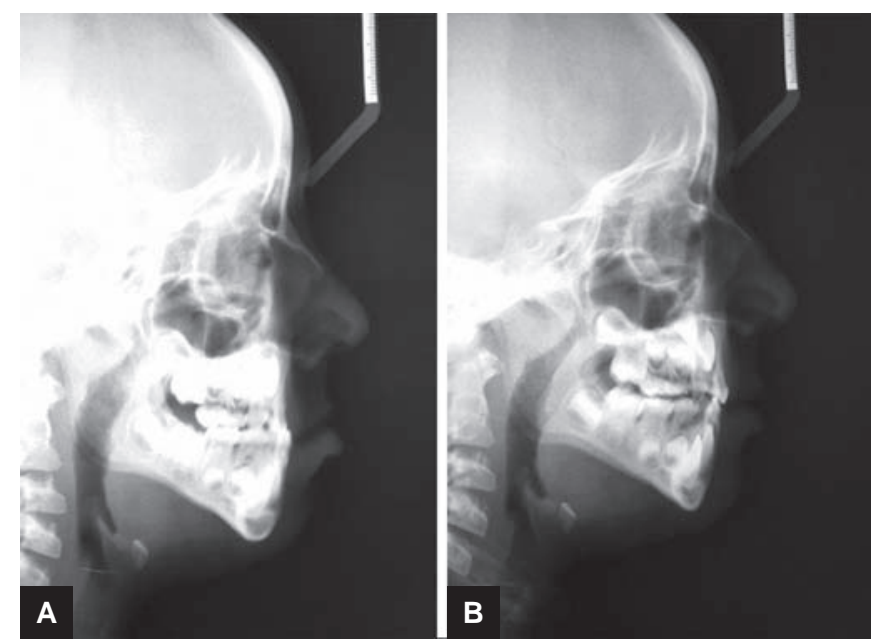

Figs 2A and B: (A) Lateral cephalometric pretreatment; and (B) lateral cephalometric posttreatment 


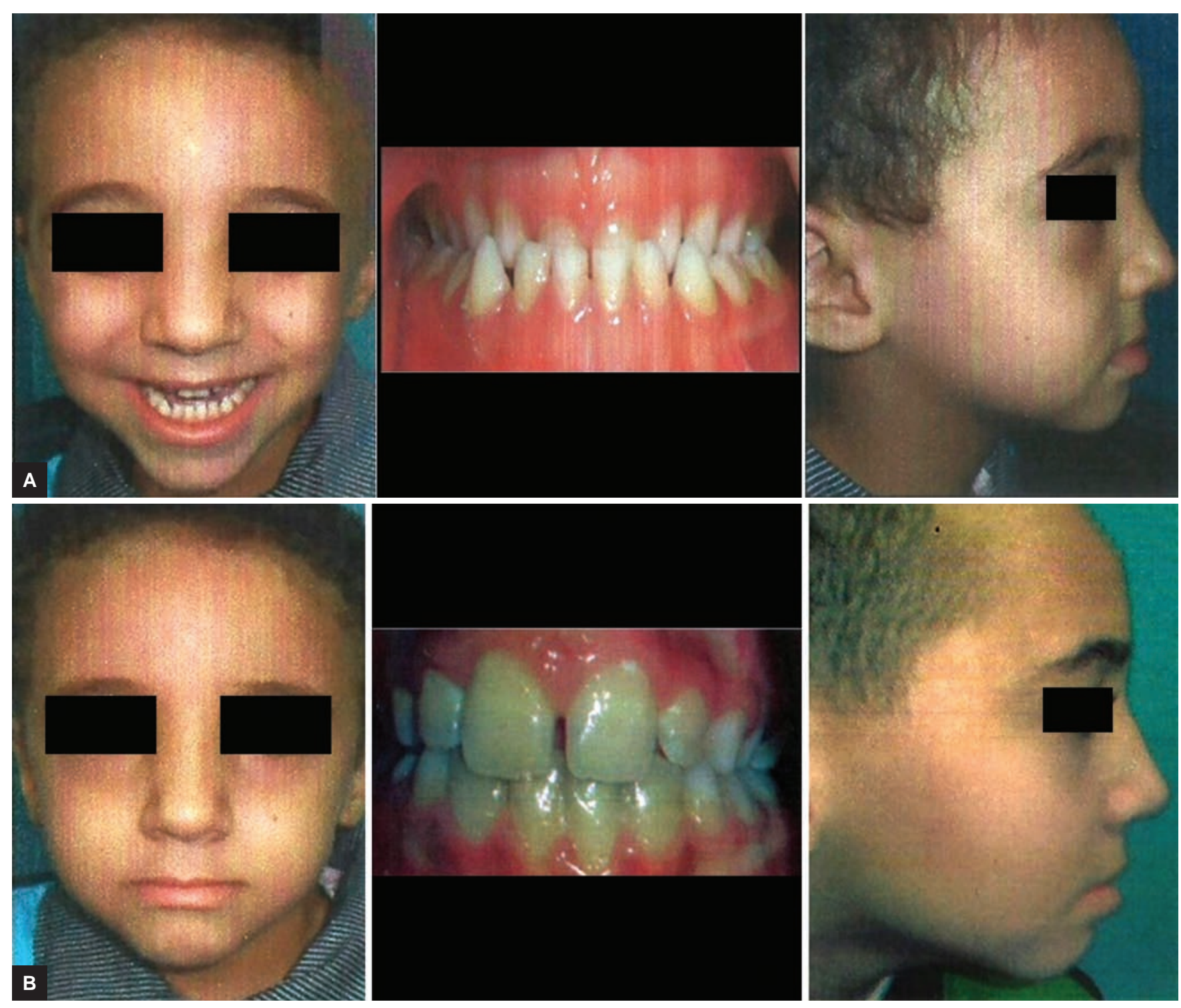

Figs 3A and B: (A) Preoperative view; and (B) Postoperative view

the patients' skeletal age, hand and wrist radiographs were used and analyzed.

Each cephalogram was traced, and the linear and angular variables were measured. The cephalometric measurements used in the study were as following: Maxillary skeletal, SNA angle, A-N perpendicular (point A to a line drawn perpendicular to the FM from $\mathrm{N}$ ), Co-ANS, and Co-A; cranial flexure, NSBa angle; mandibular skeletal: SNB angle, Pg-N perpendicular (Pg to a line drawn perpendicular to the FM from $\mathrm{N}$ ), $\mathrm{Co}-\mathrm{Go}$, Ar-Go, Co-Gn, and Go-Gn; vertical skeletal: SN-palatal plane (PP) angle, SN-GoMe angle, SN-GoGn angle, FH-PP angle, FH-mandibular plane (MP) angle, PP-MP angle, and gonial angle (Ar-Go-Me); skeletal differences: ANB angle, wits appraisal (distance between the two points of intersection of the two perpendicular lines from points $\mathrm{A}$ and $\mathrm{B}$ to the functional occlusal plane), and maxillomandibular differential (difference between Co-A and
Co-Gn) and dental measurements: Maxillary central incisor (U1)-SN angle, U1-FH angle, incisor MP angle, interincisal angle, $\mathrm{OJ}$, and $\mathrm{OB}$.

\section{Statistical Analysis}

All measurements were tabulated and analyzed. The data were analyzed using one-way analysis of variance and Tukey post hoc analysis.

\section{RESULTS}

The cephalometric measurements of the control and treated groups are shown in Table 1. Significant changes were seen in the treated group at the end of the CC therapy with improvements in the maxillary and the mandibular skeletal measurements in the treated group (Figs 3A and B). Improvement in intermaxillary skeletal variables was observed in the treated group with an average increase of ANB angle and Wits appraisal. The 
Table 1: Comparison of the changes from T1 and T2 in the control and treated groups

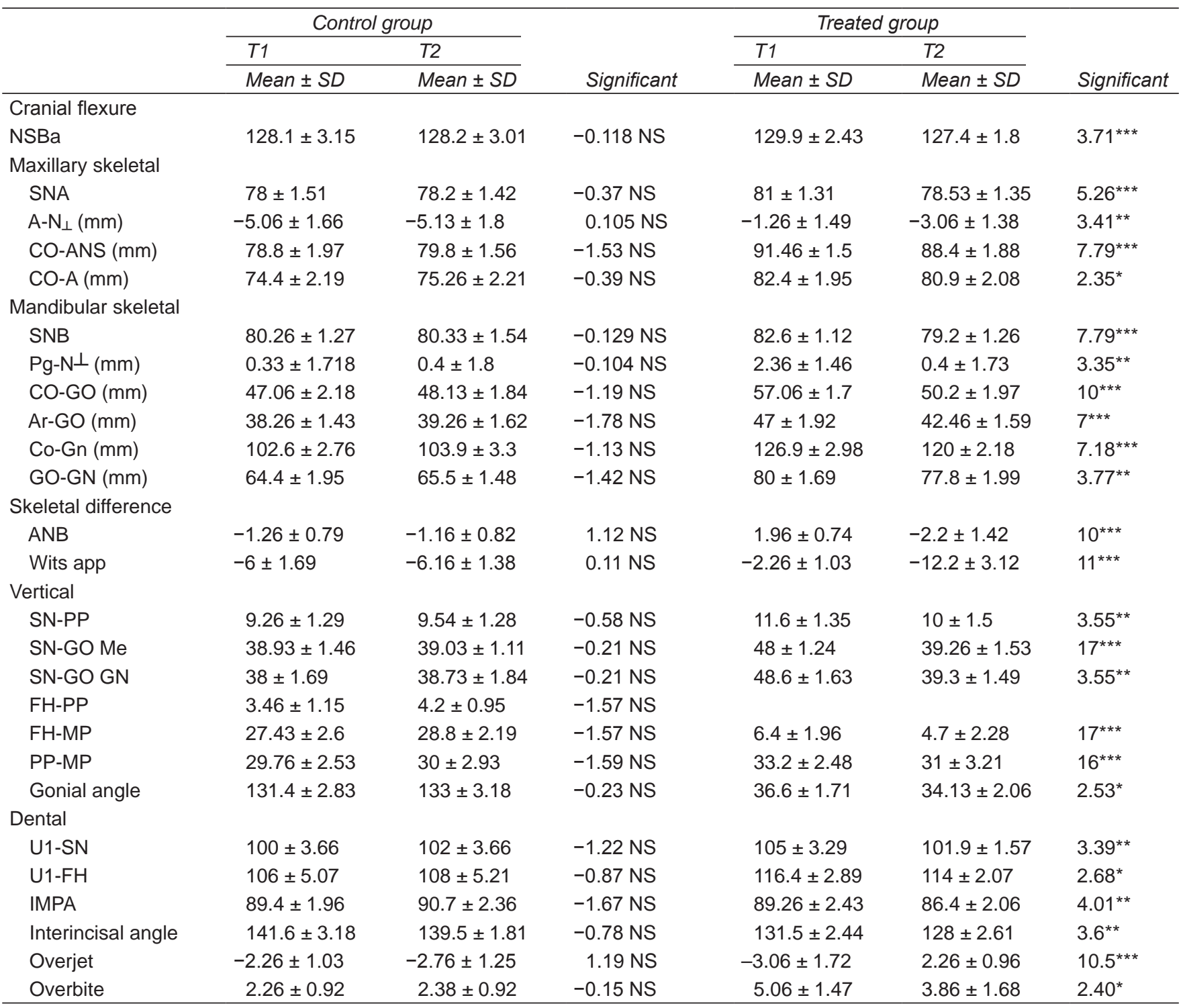

*Statistically significant at $(p<0.05)$ level; ${ }^{* *}$ statistically significant at $(p<0.01)$ level; ${ }^{* * *}$ statistically significant at $(p<0.001)$ level; SD: Standard deviation; NS: Not significant

OJ has improved significantly $(2.26 \pm 0.96)$ at the end of CC therapy. In addition, there was a significant decrease in the axial inclination of the upper and lower incisors (Table 1).

\section{DISCUSSION}

This study was conducted to analyze the dentoalveolar changes in 20 patients with class III malocclusion treated with CC therapy. The sagittal maxillary position [SNA$\left.\mathrm{AN}_{\perp}\right]$, showed significant changes at the end of $\mathrm{CC}$ therapy while Co-A and Co-ANS showed nonsignificant changes. This observation is in agreement with the studies reported by Tuncer et $\mathrm{al}^{11}$ and Altuğ et al. ${ }^{16}$ However, other studies failed to show any similar changes. $3,10,17$

This study showed significant reduction of all mandibular skeletal variables (Ar-Go, Co-Go, Co-Gn, and SNB) except Go-Gn and this agrees with earlier studies. ${ }^{3,10,11,17}$ This reduction could be explained as the result of the force of CC, which is applied directly to the mandible for trying to restrict its horizontal growth and convert it to some extent into vertical growth. ${ }^{18}$ However, a study by Deguchi and McNamara ${ }^{14}$ observed no significant changes by CC therapy in class III patients. This study showed a significant increase in ANB and Wits appraisal, which is in agreement with other studies. ${ }^{3,10,11,17}$ A significant increase in vertical angular variables (SN-Go Me, SN-Co GN) was also observed. This increase is due to the backward and downward rotation of the mandible.

Significant reduction of gonial angle was also observed in the study group, similar to the observations of the previous reports. ${ }^{3,10,17}$ This effect may be due to the applied force passing through the occipital area and the glenoid 
fossa via the condyle. ${ }^{14}$ Similar findings were reported in earlier studies. ${ }^{2,4}$ In contrast to the earlier reports, ${ }^{3,17}$ our study showed significant reduction of $\mathrm{Co}-\mathrm{Go}$.

The study showed positive OJ in all patients at end of CC therapy. There was also a significant decrease in axial inclination of maxillary anterior teeth and interincisal angle at the end of CC therapy. However, mandibular anterior teeth and $\mathrm{OB}$ showed no significant changes at the end of treatment, which is in agreement with earlier studies. ${ }^{3,17}$ A significant increase in $\mathrm{OB}$ was reported by Barrett et $\mathrm{ll}^{17}$ and this may be due to the use of Quad-helix with the CC in the treatment of class III malocclusion cases.

\section{CONCLUSION}

From the observations, it can be concluded that the CC therapy is effective for correcting skeletal class III malocclusion. It can significantly improve the dentoskeletal variables during the mixed dentition stage. Further longitudinal long-term studies are required to fully ascertain the skeletal and dental changes of CC therapy.

\section{REFERENCES}

1. Ferro A, Nucci LP, Ferro F, Gallo C. Long-term stability of skeletal Class III patients treated with splints, Class III elastics, and chincup. Am J Orthod Dentofacial Orthop 2003 Apr;123(4):423-434.

2. Chang HP, Lin HC, Liu PH, Chang CH. Geometric morphometric assessment of treatment effects of maxillary protraction combined with chin cup appliance on the maxillofacial complex. J Oral Rehabil 2005 Oct;32(10):720-728.

3. Gökalp H, Kurt G. Magnetic resonance imaging of the condylar growth pattern and disk position after chin cup therapy: a preliminary study. Angle Orthod 2005 Jul;75(4):568-575.

4. Basciftci FA, Karaman AI. Effects of a modified acrylic bonded rapid maxillary expansion appliance and vertical chin cap on dentofacial structures. Angle Orthod 2002 Feb;72(1):61-71.

5. Pedrin F, Almeida MR, Almeida RR, Almeida-Pedrin RR, Torres F. A prospective study of the treatment effects of a removable appliance with palatal crib combined with highpull chincup therapy in anterior open-bite patients. Am J Orthod Dentofacial Orthop 2006 Mar;129(3):418-423.
6. Baccetti T, Franchi L, Schulz SO, McNamara JA Jr. Treatment timing for an orthopedic approach to patients with increased vertical dimension. Am J Orthod Dentofacial Orthop 2008 Jan;133(1):58-64.

7. Graber, LW.; Vanarsdall, RL., Jr.; Vig, KW. Orthodontics: current principles and techniques. Philadelphia: Elsevier Health Sciences; 2011.

8. Insabralde NM, de Almeida RR, Henriques JF, Fernandes TM, Flores-Mir C, de Almeida MR. Dentoskeletal effects produced by removable palatal crib, bonded spurs, and chincup therapy in growing children with anterior open bite. Angle Orthod 2016 Nov;86(6):969-975.

9. Chatzoudi MI, Ioannidou-Marathiotou I, Papadopoulos MA. Clinical effectiveness of chin cup treatment for the management of Class III malocclusion in pre-pubertal patients: a systematic review and meta-analysis. Prog Orthod 2014 Dec;15:62.

10. Abdelnaby YL, Nassar EA. Chin cup effects using two different force magnitudes in the management of Class III malocclusions. Angle Orthod 2010 Sep;80(5):957-962.

11. Tuncer BB, Kaygisiz E, Tuncer C, Yüksel S. Pharyngeal airway dimensions after chin cup treatment in Class III malocclusion subjects. J Oral Rehabil 2009 Feb;36(2):110-117.

12. Uçüncü N, Uçem TT, Yüksel S. A comparison of chincap and maxillary protraction appliances in the treatment of skeletal Class III malocclusions. Eur J Orthod 2000 Feb;22(1): 43-51.

13. Uner $\mathrm{O}$, Yüksel S, Uçüncü N. Long-term evaluation after chincap treatment. Eur J Orthod 1995 Apr;17(2):135-141.

14. Deguchi T, McNamara JA. Craniofacial adaptations induced by chincup therapy in Class III patients. Am J Orthod Dentofacial Orthop 1999 Feb;115(2):175-182.

15. Allen RA, Connolly IH, Richardson A. Early treatment of Class III incisor relationship using the chincap appliance. Eur J Orthod 1993 Oct;15(5):371-376.

16. Altuğ Z, Erdem D, Rübendüz M. Investigation of the functional treatment effects of the skeletal and dental Class III anomalies on the skeletal region. Ankara Univ Hekim Fak Derg 1989 Sep;16(3):447-452.

17. Barrett AA, Baccetti T, McNamara JA Jr. Treatment effects of the light-force chincup. Am J Orthod Dentofacial Orthop 2010 Oct;138(4):468-476.

18. McNamara, JA. Treatment of patients in the mixed dentition. In: Graber, LW.; Vanarsdall, RL., Jr.; Vig, KW., editors. Orthodontics: current principles and techniques. Philadelphia: Elsevier Health Sciences; 2011. 